\title{
Epidemiology of hepatitis B virus infection in the Republic of Moldova
}

\author{
Petru larovoi, Constantin Rimis, Constantin Spinu, Maria Isac \\ Laboratory for Epidemiology of Viral Hepatitis, National Scientific and Practical Centre for Preventive Medicine, Chisinau, \\ Republic of Moldova.
}

\begin{abstract}
Background: The Republic of Moldova is considered a high endemic country with hepatitis B virus infection having a prevalence of $\mathrm{AgHBs}$ of $8 \%$ and higher. This paper describes the epidemic process and changes in the acute hepatitis $\mathrm{B}$ incidence in Moldova from 1966 until 2006. The objective was to evaluate the prophylactic measures that have led to the decline in the epidemic process of this infection.

Methodology: Epidemiological analysis of the surveillance data on acute hepatitis B incidence in the Republic of Moldova was conducted. The data were obtained from the national reporting system of infectious diseases.

Results: In the course of hepatitis B virus infection evolution in the Republic of Moldova, the epidemic process had both increasing and decreasing phases; however, starting in 1989 the incidence of this infection decreased from 66.4 to 7.5 per 100,000 population in 2006 . The decrease of the incidence has been most significant in children under 15 years, dropping from 80.8 to 2.0 per 100,000 population in the mentioned period.

Conclusions: Data collected in the Republic of Moldova shows that vaccination against hepatitis $B$ virus infection may be a very efficient preventive measure and may have a positive impact on reducing the morbidity of this infection.

Key Words: hepatitis B infection, epidemiology, epidemic process, vaccination.
\end{abstract}

J Infect Developing Countries 2008; 2(3):190-192.

Received 1 June 2007 - Accepted 17 March 2008.

Copyright (@) 2007 larovoi et al. This is an open access article distributed under the Creative Commons Attribution License, which permits unrestricted use, distribution, and reproduction in any medium, provided the original work is properly cited.

\section{Introduction}

Hepatitis B virus (HBV) infection represents a worldwide public health problem that can lead to chronic hepatitis, hepatic cirrhosis, and primary hepatic cancer. Thus, according to World Health Organization (WHO) estimations, 2 billion of the global population have contracted HBV infection and 450 million people are chronically infected and risk infection with hepatitis D virus as well [1, 2]. The prevalence of hepatitis $B$ in the world varies substantially in different territories. About $45 \%$ of the world population, including the population of the Republic of Moldova, live in highly endemic regions for HBV infection with the frequency of $\mathrm{AgHBs}$ detection is $8 \%$ and higher $[3,4]$. HBV infection represented a serious public health problem in the Republic of Moldova in the 1980s and 1990s, especially for children.

\section{Materials \& Methods}

Epidemiological analysis of the official surveillance data on acute hepatitis B infection incidence in the Republic of Moldova was conducted. The data were obtained from the national reporting system of infectious diseases. Data for acute hepatitis $A, B, C$ and $D$ were collected in the aggregated format by type of hepatitis, district, age group, and type of residence (urban or rural). Reports of acute cases of hepatitis $B$ were sent on a monthly basis. Primary data were reported by infectious diseases hospitals and general practitioners to the local Center of Preventive Medicine and from there to the National Scientific and Practical Centre of Preventive Medicine. The national standard case definitions according to the European Union case definitions were established and approved in 2007.

\section{Results}

In the Republic of Moldova, the first cases of HBV infection have been registered since 1966 with 34.3 cases per 100,000 population $(\% / 0000)$. The evolution of the acute Hepatitis $B$ epidemic process had both increasing and decreasing phases, with the maximal level being recorded in $1974(85.5 \% 0000)$ and the minimal level in 1979 
(47.9 \% 0000). Beginning in 1989, when the selective vaccination of newborns from AgHBspositive mothers was launched, the incidence of this infection decreased from $66.4^{\%} / 0000$ to 47.4 $\%$ /0000 in 1991. During the next three years (19921994) the VHB epidemic process was stable; therefore, a vaccination program for all newborns was implemented. In 1995, the National Immunization Program was approved by the Government of the Republic of Moldova and all newborns since then have been vaccinated against $\mathrm{VHB}$, according to the scheme 0,1 and 6 months. Thus the HBV infection incidence decreased from $49.9 \%$ in 1994 to $7.5 \%$ 2006 (Figure 1).

Figure 1. The hepatitis $B$ virus infection incidence in the Republic of Moldova (1966 - 2006 years).

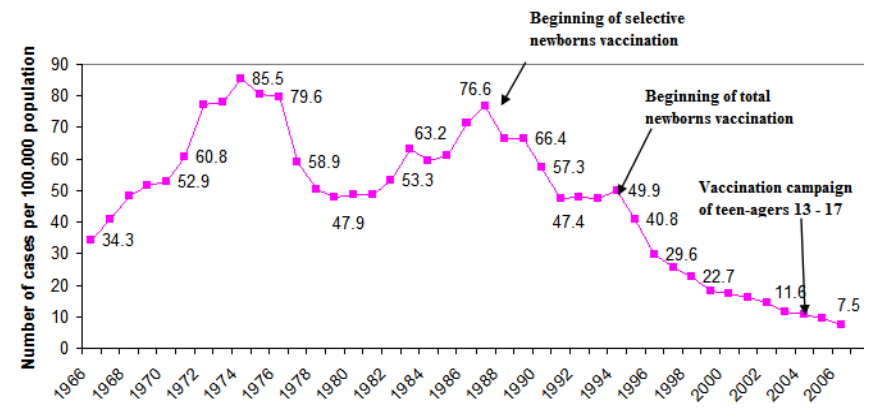

The decrease of HBV incidence has been most significant in children under 15 years, dropping from 80.8 in 1989 to 2.0 per 100,000 population in 2006. In the last 5 years in the Republic of Moldova the percentage of coverage with three doses of vaccine against hepatitis $B$ of the children is $99 \%$ (Figure 2) [5].

Figure 2. Age specific incidence of hepatitis $B$ virus infection and percentage of newborn vaccination coverage with three doses in the Republic of Moldova (1989 - 2006 years).

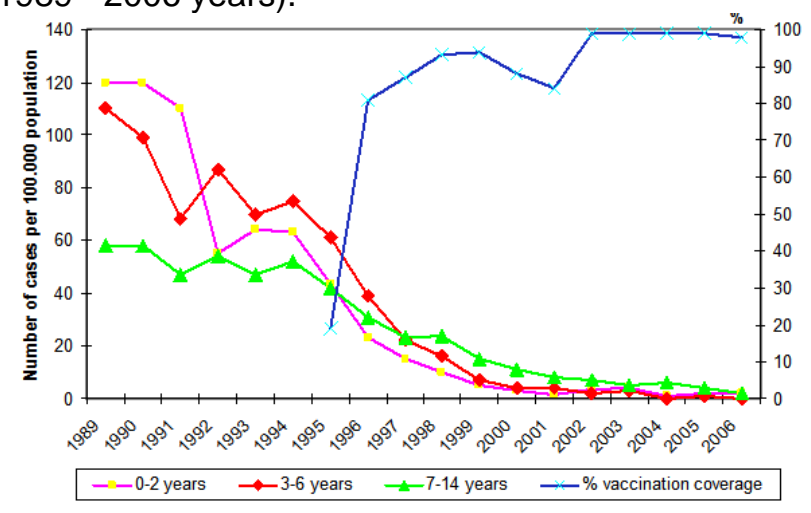

Epidemiological analysis of the VHB epidemic process shows that after the vaccination program of newborns was implemented, the distribution of morbidity changed by age groups. From 1990 to 1992, in the pre-universal newborn vaccination period, most of the cases of acute HBV infection were recorded among children aged up to 7 years, while in the course of 2002 to 2004, ten years after the universal newborn vaccination program started, the highest morbidity by acute HBV infection was registered in teenagers in the age group 15 to 19 years (Figure 3 ). This fact led to the decision in 2005 to vaccinate teenagers against HBV infection.

Figure 3. The distribution of hepatitis B virus infection incidence by age groups in pre- and post-vaccination periods of newborns in the Republic of Moldova.

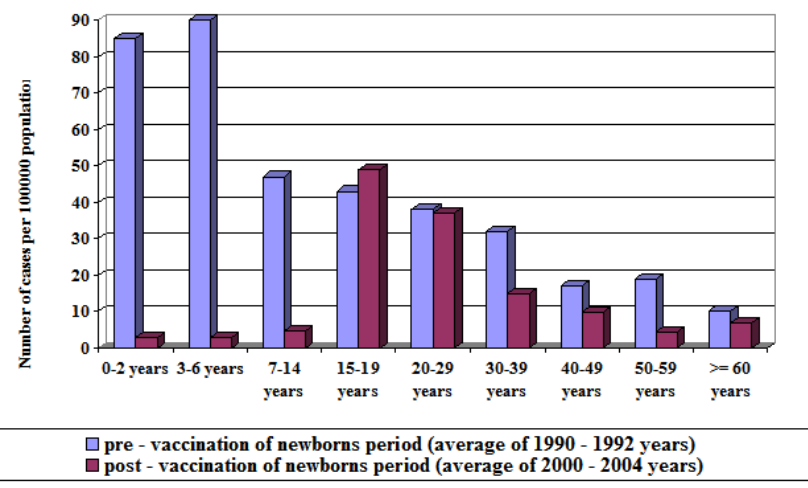

Over the years, specific measures to control HBV infection have been found to be insufficient. The appearance of new forms of viral hepatitis requires implementing non-specific prophylactic measures. Consequently, in 1997 the government of the Republic of Moldova issued Decision No. 507 approving "The National Program on Prevention and Control of Hepatitis B, C and D" legislates the implementation of both specific and non-specific prophylactic measures. Hence, concurrently with vaccination of newborns against HBV infection, vaccination of risk groups was launched as well, including health care workers and medical students; the members of families with patients with chronic hepatitis; the in-patients from the departments of hemodialysis and pneumoftisiology etc. Likewise, a series of other measures was implemented, including using disposable medical equipment; testing blood donors for AgHBs by using high sensitive and specificity test-systems; reducing the application of 
injectable remedies; and optimizing the sterilization of repeatedly used medical equipment.

\section{Discussion}

While more comprehensive correlative studies are required, the reduction of the morbidity by acute hepatitis $B$ is associated with the prophylactic measures that were introduced during the last 15 years in the Republic of Moldova such enforcing the use of single-use needles and a routine vaccination program for children and health care workers.

The experience of the Republic of Moldova proves that vaccination against HBV infection is a very efficient preventive measure. In order to achieve more significant results in controlling VHB it is necessary, along with vaccination of the newborns, healthcare workers and medical students, to vaccinate people from families of patients with chronic hepatitis, adolescents and the population of fertile age adults, as well as to improve the implementation of non-specific measures. All these measures are included in the new National Program on Prevention and Control of HBV, HCV and HVD in the Republic of Moldova for the period of $2007-2011$.

\section{References}

1. WHO/CDS/CSR/LYO/2002.2: Hepatitis B.
2. Emiroglu N. Immunization Programme and Prevention / control of Hep B European Region of WHO. EUROHEP.NET Meeting, April 21, 2005. Available: http://www.eurohep.net/files/presentations/MALS61Emiro glu.pdf. Accessed May 2007

3. Atkinson W, Hamborsky J, Mclntyre L, Wolfe $\mathrm{CH}$., eds. (2006) Centers for Disease Control and Prevention. Epidemiology and Prevention Vaccine - Preventable Diseases 9th ed. Washington DC: Public Health Foundation. p.207-231

4. Levitt A, Vorsters A, Emiroglu N, Goldstein S, Godal T, Kane M, Popovic D, Wiersma S, Van Damme P (2004) Strenthening immunization systems and introduction of hepatitis B vaccine in Central and Eastern Europe and the Newly Independent States. Third regional conference on prevention and control of hepatitis B in Central and Eastern Europe and Newly Independent States. Kyiv, Ukraine, May 25-28, 2004. ISBN: 9073155444.

5. WHO/UINCEF (2007) Review of national Immunization Coverage 1980 - 2006. The Republic of Moldova. Available:http://www.who.int/immunization_monitoring/dat a/mda.pd. Accessed May 2007.

Corresponding Author: Constantin Rimis, Kentford Bld, 202 Stefan cel Mare Ave. 8th floor, Chisinau MD2004, Republic of Moldova, Tel: (373 22) 7527 68, Fax: (373 22) 7555 10, Mob; 37369501 768, E-mail: crimis@phh.md

Conflict of interest: No conflict of interest is declared. 